\title{
Correction to: The application of deep learning for the classification of correct and incorrect SNP genotypes from whole-genome DNA sequencing pipelines
}

\author{
Krzysztof Kotlarz ${ }^{1} \cdot$ Magda Mielczarek $^{1,2} \cdot$ Tomasz Suchocki $^{1,2} \cdot$ Bartosz Czech $^{1} \cdot$ Bernt Guldbrandtsen $^{3}$. \\ Joanna Szyda ${ }^{1,2}$
}

Published online: 12 October 2020

(C) Institute of Plant Genetics, Polish Academy of Sciences, Poznan 2020

Correction to: Journal of Applied Genetics (2020).

https://doi.org/10.1007/s13353-020-00586-0

The original version on this paper contained an error. Figure 5 was published with the same image of figure 4 . The correct figure 5 is presented here. The original article has been corrected.

The online version of the original article can be found at https://doi.org/ 10.1007/s13353-020-00586-0

Joanna Szyda

joanna.szyda@upwr.edu.pl

1 Biostatistics Group, Department of Genetics, Wroclaw University of Environmental and Life Sciences, Kozuchowska 7, 51-631,

Wroclaw, Poland

2 Institute of Animal Breeding, Balice, Poland

3 Animal Breeding Group, Department of Animal Sciences, University of Bonn, Bonn, Germany 
Fig. 5 Classification of validation data by the different algorithms, based on the probability cutoff thresholds estimated for the F1 or SUMSS metrics. The numbers above columns represent $\mathrm{TP}$ percentages of true positive results, $\mathrm{TN}$ - percentages of true negative results, $\mathrm{F} 1$ - values of the F1 metric
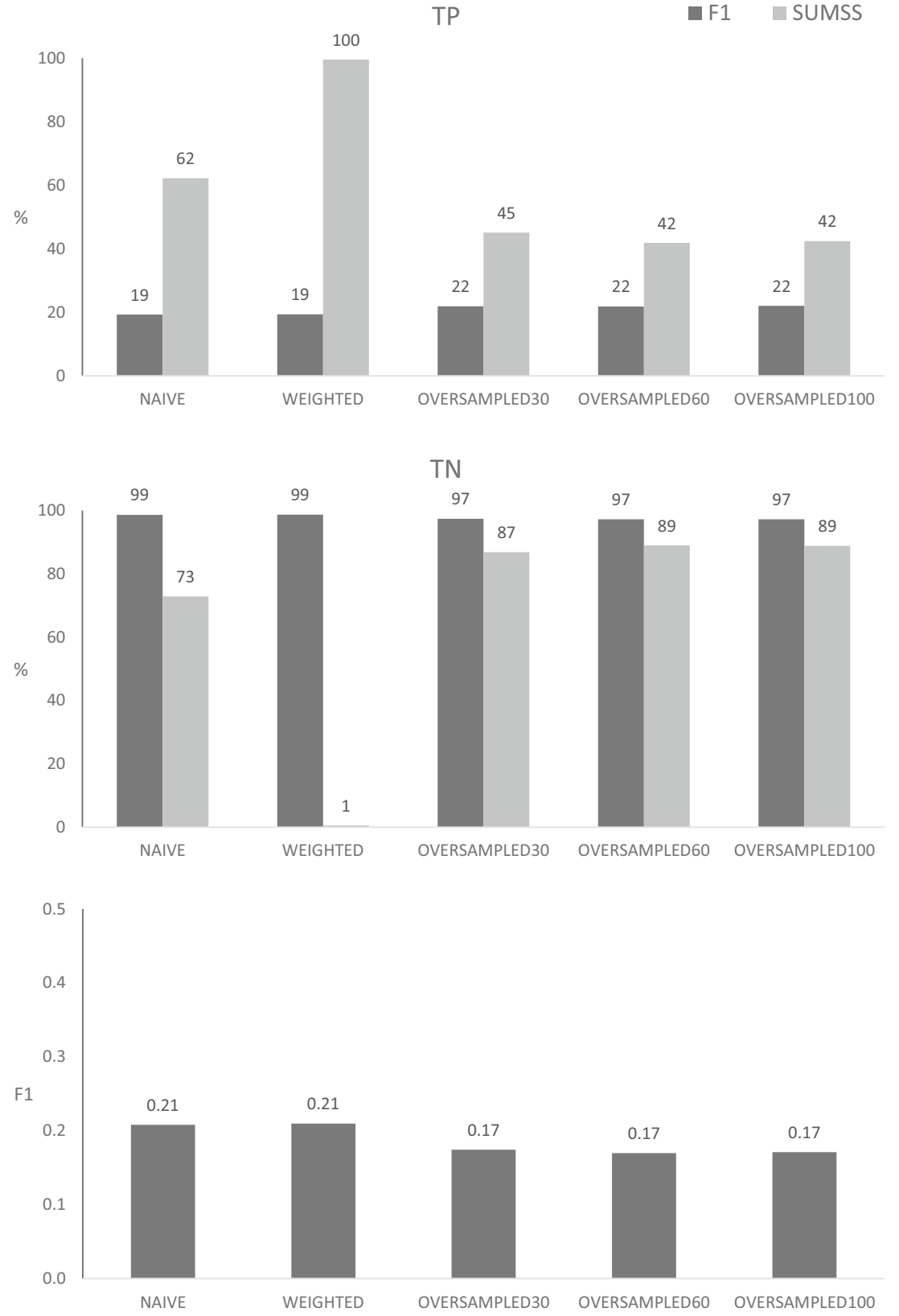

Publisher's note Springer Nature remains neutral with regard to jurisdictional claims in published maps and institutional affiliations. 